\title{
UNA PROPUESTA FUNCIONAL Y TIPOLÓGICA DE DESCRIPTORES SINTÁCTICOS PARA EL MAPUDUNGUN
}

\author{
A functional and typological proposal of syntactic descriptors for mapuche
}

language

\section{Rodrigo Becerra Parra*}

\section{Resumen}

En este artículo se analiza la pertinencia de los descriptores sintácticos en uso en la lengua mapuche con el fin de enfrentar teóricamente la postura que espera reflejar su organización particular, con aquella otra que valora situarla en el concierto mundial de las lenguas. En el marco de la "Gramática Funcional Tipológica" de Talmy Givón (1983-1995-2001), este trabajo reconoce la importancia de las propiedades formales y pragmáticas y de su interrelación para el estudio de la sintaxis. Así, junto con discutir la denominación "persona focal", este estudio presenta un análisis formal e informativo de la lengua mapuche. Como parte del primero, se analizan las propiedades de la "persona focal", en tanto que el segundo considera el estudio de un corpus de siete cuentos mapuches. Ambos muestran que la "persona focal o axial" cumple de forma sistemática con las propiedades de la categoría "sujeto".

Palabras clave: Lengua mapuche, perspectiva funcional-tipológica, persona focal, sujeto gramatical.

\section{Abstract}

In this article, the adequacy of syntactic descriptors used in mapuche language I discuss, in order to confront theoretically those who want to reflectits particular syntactic organization, and those who prefer to put it into universal parameters. Sustained in the "Functional Typological Grammar" of Talmy Givón (1983-1995-2001), this paper recognize the importance of formal and pragmatic properties - as well as their connection - for the study of syntax. In this basis, in addition to the discussion about the concepts in use, an analysis of mapuche grammatical categories is presented. So, the formal and pragmatic properties of "focal person" in mapuche are analized, and a corpus based study realized over seven mapuche tales is presented. Both parts of the study show that mapuche "focal person" is completely congruent with the formal and pragmatic properties of "subject".

Key words: Mapuche language, functional-typological perspective, focal person, grammatical subject.

\section{INTRODUCCIÓN}

En este trabajo se discute la pertinencia de los distintos descriptores sintácticodiscursivos que son utilizados en la bibliografía acerca de la lengua mapuche o mapudungun. En primer lugar, el análisis se centra en la propuesta descriptiva de Salas (1971-1978-1979), debido a la influencia que ésta ha ejercido y que sigue teniendo en las elecciones terminológicas y conceptuales en los estudios del mapudungun. Los parámetros considerados son las propiedades sintáctico-discursivas de los principales 
roles gramaticales, por lo que se realiza una caracterización de las mismas. En segundo término, se presenta una discusión de las relaciones entre propiedades sintácticas y pragmáticas, a la luz de la Gramática Funcional Tipológica de Givón (2001), con el fin de fundamentar funcional, diacrónica y tipológicamente la adecuación de los distintos descriptores en uso en la lengua mapuche.

Gran parte de los estudios de la estructura sintáctica mapuche que se han realizado a la fecha, se inscriben en una tradición que se ha acercado a este ámbito de manera preferente, a partir de los morfemas verbales de persona. Esto podría explicarse por ser un área aún poco estudiada en la lengua mapuche, y por la fuerte atracción que ha generado el estudio del verbo, considerando la tendencia polisintética de la lengua y la existencia de diversas categorías de dichos morfemas.

De este modo, Salas (1971-1978-1979), reconociendo algunas particularidades del sistema mapuche, desestimó la pertinencia de los conceptos "sujeto" y "objeto", para describir adecuadamente sus relaciones gramaticales. En la práctica, su influencia ha redundado en la toma de posición de otros investigadores, respecto a los descriptores señalados. Así, mientras algunos han seguido esta opción descriptiva (Grimes, 1985; Lagos et al., 2009; Rivano, 1988, 1991; Zúñiga, 2006a), otros autores han preferido el concepto de "sujeto" (Arnold, 1996; Baker, 2003; Baker y Fasola, 2007; Fernández Garay, 1982; Golluscio, 2010; Harmelink, 1996; Smeets, 2008; Zúñiga, 2006b). ${ }^{1}$

Sin embargo, la propuesta de Salas (1971-1978-1979) también ha sido objeto de matizaciones y críticas por parte de algunos autores que la han suscrito, quienes han observado la existencia de inconveniencias terminológico-conceptuales. Grimes (1985) y Lagos et al. (2009), por ejemplo, consideran el término "focal", pero lo evitan por la posible asociación con la función informativa "foco". Asimismo, estos autores señalan el carácter topical de la principal persona gramatical, lo que refrenda las aprensiones respecto al término "focal". Cabe destacar también, que en Salas (1992) se observa un uso concurrente de sus descriptores, junto con la de la gramática estándar.

El presente trabajo propone una lectura de estas discrepancias, fundada en un enfoque funcional y tipológico, con el objetivo de ubicar la discusión en el marco amplio del estudio de las relaciones gramaticales en las lenguas del mundo. Junto con lo anterior, se estudian las características formales de la lengua mapuche que, aun siendo particulares, no la sitúan fuera de posibles generalizaciones, sino que por el contrario indican procedimientos de índole cognitiva que pueden enriquecer las explicaciones de tipo funcional.

\footnotetext{
${ }^{1}$ Zúñiga (2006b) utiliza el concepto de "roles gramaticales", distinguiendo entre S (único rol de una cláusula intransitiva, "sujeto"), A (rol agente en una transitiva) y O (rol paciente en una transitiva). Por lo tanto, ocupa ocasionalmente el término "sujeto", aunque con otra base teórica. El término "objeto" es utilizado de forma muy acotada.
} 


\section{GRAMÁTICA FUNCIONAL TIPOLÓGICA}

La Gramática Funcional Tipológica (GFT), formulada por Givón (1983-19952001-2009) como marco explicativo y descriptivo del lenguaje y de las lenguas, se inscribe en la tradición norteamericana que reconoce antecedentes en Sapir (1994) y Greenberg (1966). De esta manera, la GFT defiende una perspectiva funcional para los estudios del lenguaje, según la cual éste se orienta y organiza teleológicamente. Es decir, se considera que la forma del lenguaje se vincula permanentemente a sus funciones, tanto en su origen diacrónico como en su manifestación sincrónica, por lo que se evita un acercamiento a la gramática como sistema autocontenido en su forma o en un nivel de organización desvinculado del uso.

En esta teoría, la gramática forma parte del sistema del código comunicativo que, junto con el sistema de representación cognitiva de la experiencia, corresponden a los dos subsistemas básicos del lenguaje (Givón, 2001-2009). En su origen, la gramática, encargada de la codificación automatizada de la experiencia, se construye en la interacción de la vida cotidiana, por lo que simultáneamente cumple el rol de codificar - mediante procedimientos formales - los contenidos proposicionales (semántica) y establecer la coherencia discursiva (pragmática).

En esta tarea, la gramática realiza una correlación entre forma linguística y función que, sin embargo, dista de ser biunívoca, pudiendo una forma expresar más de una función, y una función ser vehiculizada por más de una forma. De hecho, las lenguas humanas, en continuo cambio, utilizan los recursos disponibles en un momento dado para la expresión de una función comunicativa. Estas elecciones cotidianas, relacionadas a constreñimientos cognitivos y del propio sistema, están en la base de los procesos de extensión funcional y de cambio lingüístico. Como resultado, el reanálisis del sistema gramatical permite modificaciones continuas en el uso, al tiempo que la estructura tiende a mantenerse más estable, lo que, por otra parte, permite conocer la diacronía del proceso de cambio funcional.

La constatación de que una misma función puede ser actualizada por más de una forma (tanto intra como interlingüísticamente), permite postular una perspectiva tipológica para el estudio de la gramática, según la cual: a) Son las funciones comunicativas - y no la similitud estructural — los parámetros fundamentales para analizar el código gramatical y, por ende, b) La comparación interlingüística es posible y aceptable a partir de la identificación de meta-funciones o dominios funcionales (Givón, 2001). Así, en la GFT, la comparación interlingüística es fundamental, tanto para conocer las funciones comunicativas básicas, como para identificar las construcciones de distinto orden que las actualizan. Por tanto, un enfoque tipológico no supone desconocer las particularidades de las lenguas, sino valorarlas como expresión diversa de dominios funcionales humanos, enfrentados a contextos de uso reales.

Como consecuencia, la GFT propone el uso translingüístico de descriptores gramaticales, considerando categorías prototípicas de los mismos. La doctrina del prototipo permite, por una parte, caracterizar las categorías a partir de propiedades 
de aparición frecuente y de "parecidos de familia" (se excluyen las propiedades "necesarias y suficientes") y, por otra, mantener la fidelidad a un marco teórico, que considera los compromisos adaptativos en la emergencia y en el uso del lenguaje. Por lo tanto, en esta teoría se acepta la gradación en la adscripción de un caso cualquiera (v.gr., la principal persona gramatical en mapuche), a una categoría específica ( $v . g r$., sujeto).

Por consiguiente, conceptos gramaticales como "sujeto", "objeto" y "tópico" corresponden a categorías para las cuales pueden reconocerse distintas propiedades, algunas más o menos representativas de una lengua, de un grupo de lenguas o de la categoría, en tanto instanciación de un dominio funcional universal. Así, por ejemplo, Givón (2001), a partir de la definición de Keenan (1976)² definió el sujeto de manera amplia mediante sus propiedades más estables en una cláusula simple (es decir, principal, declarativa, activa y afirmativa). Tales propiedades tienen una base pragmática reconocible, es decir, una motivación funcional.

\section{¿POR QUÉ “PERSONA FOCAL”?}

Los verbos finitos mapuches expresan de forma obligatoria las categorías de modo, persona y número mediante la denominada "flexión verbal obligatoria finita" (Salas, 1979). En su interior, la adscripción del verbo a las categorías de persona y número, relaciona a éste con el argumento que ocupa el principal rol gramatical. El concepto de "persona focal", "axial" o "eje" propuesto por Salas (1971-1979), indica justamente que el verbo está personalizado (o "focalizado", en la terminología de Salas), estableciendo una concordancia con el argumento principal.

Salas (1979) propuso el concepto de "focal", a partir del reconocimiento de que toda oración se construye fijando como centro la persona que se conceptualiza como axial, por lo que las acciones se centran en ella. Asimismo, en la codificación de las interacciones, en las que el verbo mapuche puede manifestar una marca argumental adicional ("persona satélite" o "interactuante" en Salas), el verbo aparece

\footnotetext{
${ }^{2}$ Según Keenan (1976), pueden definirse translingüísticamente una serie de características recurrentes (pero no "necesarias y suficientes") del sujeto gramatical en cláusulas simples. Keenan postuló una definición de tipo "multidimensional", de modo tal que se producen variaciones de grado en la adscripción de un caso particular de sujeto (en una lengua y en una cláusula determinada) respecto al conjunto de características. En total, se reconocieron treinta propiedades que se organizaron en cuatro grupos: a) Propiedades de autonomía (a saber, existencia independiente, indispensabilidad y referencia autónoma), b) Propiedades de marca de caso (preeminencia del sujeto para recibir marca de caso; cambio de dichas marcas con la causativización y nominalización); c) Roles semánticos (predictibilidad del rol semántico del sujeto a partir de la forma del verbo principal; preeminencia de la aparición del rol agente en las cláusulas simples y en los imperativos); y d) Dominio inmediato. Cabe destacar que la propiedad de autonomía incluye la topicalidad y la referencialidad presupuesta que son tomados por Givón (2001) como parte fundamental de su teoría, al reconocer la sintaxis como "pragmática gramaticalizada". Finalmente, Keenan distingue y jerarquiza tres tipos de propiedades, dependiendo de la frecuencia con que tienden a presentarse en el sujeto de cláusulas derivadas (no simples). Así, el sujeto de una cláusula derivada que presente una característica, también presenta las características inferiores de la jerarquía.
} 
"centrado" en la persona focal. Esta centralidad de la persona "focal" es tanto conceptual como gramatical. Por una parte, la lengua mapuche concibe una jerarquía de interacción de naturaleza deíctica, a partir de la cual, las personas más altas (las dialógicas o participantes del acto de habla) se consideran preeminentes (sobre las no dialógicas), ${ }^{3}$ y por otra, tal jerarquía está gramaticalizada de modo tal, que las personas más altas contraen de manera obligatoria el rol "axial". De este modo, si en una cláusula finita el hablante decide incluir a la primera persona en el discurso, o referirse a algo que le esté subordinado, ésta siempre será "axial" (1) y (2)

(1) Ñi chaw tañi chachay laku-ye-fi-ñ (Coña, 2000:203). ${ }^{4}$ Mi padre su papito abuelo. Paterno-llevar-Obj3Pac-Ind1 $\mathrm{s}^{5}$

(Al) papito de mi padre lo llevo por abuelo paterno.

(2) “Amu-a-n may [...]” pi-ñma-nge-n ñi ñuke (Coña, 2000:196).ir-FUT-Ind1s sí decirAPL-VP-Ind1s mi madre

"Iré pues [...]" (me) le dijeron a mi madre. (Lit.: "Me fue dicho a mi madre").

En estos ejemplos puede observarse, adicionalmente, que en mapuche no existe una restricción respecto a qué persona contrae el rol activo. En consecuencia, tanto la "focal" como la "satélite" pueden adquirir el papel semántico de agente o de paciente. Así, la identificación de una jerarquía de personas gramaticales, que redunda en la preferencia de ciertas personas para contraer una función sintáctica, así como su independencia de las funciones semánticas que contraen dichos argumentos, llevó a Salas (1971-1979) a evitar el concepto de sujeto que había sido utilizado por Augusta (1903) y Lenz (1944) y, más aún, divulgar sus propios descriptores.

En particular, Salas (1979) consideró que las funciones sintácticas tradicionales estaban unidas a un aparataje conceptual que no hacía sino oscurecer las descripciones, al equiparar la estructura gramatical mapuche a aquélla de las lenguas clásicas y europeas. Por ejemplo, indicó que la asociación del sujeto a un rol semántico activo, así como del objeto a uno pasivo, redundaría en la proliferación de funciones sintácticas artificiales en mapuche. Advirtió, además, acerca del uso de funciones sintácticas variables y acomodaticias para un mismo

\footnotetext{
${ }^{3}$ Además, según Rivano (1991), las interacciones en mapuche se organizan metafóricamente en términos de proximidad y orientaciones en un espacio en el cual la "persona eje" constituye el centro deíctico.

${ }^{4}$ Los ejemplos extraídos de publicaciones se indican en un paréntesis que contiene la fuente (Pascual Coña, 2000; Adalberto Salas, 1979; Rodrigo Becerra, 2009), seguida del número de página. Los ejemplos sin indicación corresponden a expresiones recopiladas de forma oral por el autor. En todos los casos, se trabajó directamente con el mapudungun, no con las traducciones previas. Asimismo, se proponen traducciones más adecuadas a la forma y significado del enunciado.

${ }^{5}$ Simbología utilizada en los ejemplos: 1) primera persona, 2) segunda persona, 3) tercera persona, AF: afirmativo; Ag: rol semántico agente; APL: aplicativo; DEI: deíctico (de acción completa); EST: estativo; EXP: expresivo; FUT: futuro; Ind: modo indicativo o real; INF: forma verbal infinita; Obj: objeto (persona satélite de Salas); Pac: valor semántico paciente o no-agente; RFX: reflexivo-recíproco; s: singular; SUJ: sujeto; VP: morfema que indica propiedad y construcción pasiva.
} 
morfema de persona, y para el sintagma nominal correferente. ${ }^{6}$ Del mismo modo, subrayó la dificultad de usar los conceptos de sujeto/objeto en la "incorporación de satélite" (interacción de primera agente y segunda paciente), ya que en estos casos la "persona axial" corresponde a la sumatoria de los interactuantes.

\section{¿POR QUÉ “SUJETO”?}

Si bien valoramos el reconocimiento de Salas (1979) de las particularidades del sistema gramatical mapuche, ya que guardó fidelidad a los "significados émicos" de los morfemas y de sus casilleros, consideramos que, al desechar las funciones sujeto y objeto, el autor estaba traspasando las asociaciones semánticas que éstas tenían en otras lenguas. En el presente artículo se opta por una concepción de las relaciones gramaticales que, reconociendo las particularidades de la lengua mapuche, alcance una comprensión y descripción de éstas desde su lógica organizativa, es decir, considerando los parámetros funcionales que han sido gramaticalizados en su emergencia. En este sentido, una visión amplia de las relaciones gramaticales puede identificar aquellos aspectos comunes reconocidos translingüísticamente.

De este modo, las desventajas del uso de los descriptores "sujeto" y "objeto", señaladas por Salas (1979), se desvanecen con la identificación de que la estructura semántica difiere de la sintáctica, ${ }^{8}$ así como con la adopción de funciones sintácticas y semánticas pertinentes y con validez tipológica. En definitiva, al distinguir las funciones sintácticas de las semánticas, no cabe asociar unívocamente el sujeto al agente y el objeto al paciente. Si bien existiría una tendencia en las lenguas del mundo para realizar esta asociación, al menos en las cláusulas simples (Givón, 2001; Keenan, 1976), existen lenguas con sistemas de inversión — como el mapuche (Arnold, 1996; Zúñiga, 2006b) en que es posible establecer el mapeo contrario (sujeto-paciente y objeto-agente).

\footnotetext{
${ }^{6}$ Ya Lenz (1944:239) había señalado que “en las 'transiciones', [las terminaciones personales] a veces corresponden al sujeto, a veces al complemento y, a veces, a los dos". Salas (1979:250-253) criticó la aplicación de estas funciones, según las cuales el objeto directo implicaría el tema (como rol semántico), el indirecto, el destinatario, y el agente no podría ser contraído sino por el sujeto o el

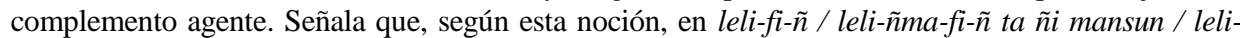
$\tilde{n} m a-\tilde{n} m a-f i-\tilde{n} \tilde{n} i$ mansun ñ fotüm, el morfema - $f i$ tendría que ser asociado a distintas funciones: en el primer caso, al complemento directo, en el segundo, al indirecto y, en el tercero, a un complemento indirecto de segundo grado. En consecuencia, habría que derivar varias estructuras paralelas artificiales en el verbo mapuche.

${ }^{7}$ Salas (1979:256) utiliza el mismo ejemplo de Lenz (1944:239) para criticar su uso de las funciones sujeto y complementos. En "elu-e-yu" (dar-1s.satélite-1d.focal) "yo te doy", literalmente más similar a "darte nosotros dos" o "darte yo contigo", la terminación personal parece incluir el sujeto y el complemento, al menos en la concepción tradicional de estas funciones.

${ }^{8}$ La diferencia entre ambas estructuras, comprobada por medio de un "test de disociación" (Givón, 2001), provendría diacrónicamente de la emergencia de cada una. En el mapuche, ambas estructuras ya han sido distinguidas con anterioridad: Arnold, 1996; Baker, 2003, 2006; Baker y Fasola, 2007; Fernández-Garay, 2001.

9 Zúñiga (2006b) también reconoce un sistema de inversión en el mapudungún, pero no define las relaciones gramaticales de la forma como se hace en este trabajo.
} 
En resumen, al diferenciar una estructura semántica de una sintáctica, se esfuma la aprensión por el surgimiento de funciones acomodaticias y variables para un mismo elemento funcional. Utilizando el mismo ejemplo de Salas (1979), a partir del test de disociación es posible comprobar la separación de las estructuras semántica y sintáctica. En (3), mientras las relaciones gramaticales sujeto y objeto se asocian, respectivamente, a las marcas morfológicas $-\tilde{n}$ y $-f i$, el mapeo del objeto con los roles semánticos varía: en el primero corresponde al paciente, y en el segundo al receptor/benefactivo ${ }^{10}$

(3) a leli-fi-ñ (Salas, 1979:253).

mirar-Obj3Pac-Ind1s

"Lo miré (a algo/alguien)".

b leli-ñma-fi-ñ ta ñi mansun (Salas, 1979:253).

mirar-APL-Obj3Pac-Ind1s AF su buey

"Se lo miré (a alguien) su buey".

Givón (2001), a partir de la definición de Keenan (1976), reconoce que las propiedades más universales del sujeto corresponden a las pragmáticas, mientras que las menos universales, a las morfológicas. De esta manera, de más a menos universales, se tiene: propiedades de referencia y topicalidad > propiedades de control de construcciones $>$ orden de palabras $>$ concordancia gramatical $>$ marcas de caso nominal. Como resultado, el reconocimiento de la función sujeto implica gradación, encontrándose el conjunto más prototípico de propiedades en una cláusula simple.

A la inversa, la identificación de las relaciones gramaticales se realiza a partir de su tendencia a presentar una gama de propiedades de distinto orden, reconociéndose, además, que las propiedades exhibidas por una misma función varían dependiendo del tipo de cláusula en que se encuentre (Givón, 2001; Keenan, 1976).

En el mapuche, las personas "axiales" o "focales" de Salas (1979) corresponden a la definición de sujeto de Keenan (1976) y Givón (2001). Es posible mostrar que la principal entidad gramatical cumple un amplio rango de las propiedades del sujeto, desde algunas de las menos extendidas, hasta las más universales. En cuanto a las primeras, presenta algunas de las propiedades de "codificación abierta": concordancia con la forma verbal finita (reconocida ya por Augusta, 1903) y, orden de palabras relativamente fijo respecto al verbo y al objeto en las cláusulas transitivas (Rivano, 1988; Arnold, 1996). En este sentido, Rivano (1988) interpretó una asimetría de las personas "axial" y "satélite", como una prueba estructural de la existencia de una función "sujeto" distinguible del "predicado".

Además, el sujeto en mapuche presenta propiedades de control de algunas construcciones, por ejemplo, en la construcción de la pasivización (4), inversión (5), reflexivización (6), continuidad de SN en subordinadas (6) y correferencia anafórica en cláusulas coordinadas (7). Finalmente, como es de esperar, también manifiesta las propiedades funcionales de referencia y topicalidad (vid. infra).

${ }^{10}$ Benefactivo, siguiendo la nomenclatura de roles reconocidos en Givón (2001). "Receptor afectado", según Golluscio (2010). 
(4) a Activa

"Pra-kawellu-imi nga?" pi-f(i)-i [tüfachi kona] (Coña, 2000:300)

subir-caballo-Ind2s EXP decir-Obj3Pac-Ind3 este mocetón

“¿Montaste a caballo pues?, le dijo (a) este mocetón”.

b Pasiva

"Pra-kawellu-imi nga?" pi-nge-i [tüfachi kona].

subir-caballo-Ind2s EXP decir-VP-Ind3 este mocetón

“Montaste a caballo pues?, (le) fue dicho (a) este mocetón”.

En (4), se observa que pasivizar una cláusula activa implica la democión del sujeto y la promoción del objeto directo (tüfachi kona) (4a) a la función de sujeto (4b). Esto se logra en mapuche mediante la eliminación de la referencia al agente, a través del uso de un morfema (-nge) que indica propiedad o característica persistente. Aunque este sufijo fue dado a conocer por Salas (1979) como "tercera persona indefinida agente", en realidad su referencia a una persona es totalmente secundaria y, en realidad, sólo contextualmente pertinente y relevante.

Por otra parte, la construcción de cláusulas inversas en mapudungún está regida tanto por el sujeto como por el objeto gramatical. El verbo mantiene su referencia a la persona más topical como sujeto (vid. infra), mientras que la otra sigue marcada como objeto, pero se invierte la adscripción de los roles gramaticales respecto a los roles semánticos, por lo que el sujeto queda marcado como paciente y el objeto como agente (5)

(5) a Directa

Feimew feichi wentru feipi-f(i)-i tichi soldao (Coña, 2000:429).

Entonces ese hombre decir-Obj3Pac-Ind3 ese soldado

"Entonces ese hombre le dijo a ese soldado".

b Inversa

[feichi wentru] feimew feipi-e-i-eu tichi soldao (Coña, 2000:429).

ese hombre entonces decir-ObjAg-Ind3-Obj3 ese soldado

"[Ese hombre] entonces era dicho (por) ese soldado", “... le dijo ese soldado".

En cuanto a las reflexivas, puede demostrarse que éstas son gobernadas por el argumento sujeto, no por el objeto. En efecto, el argumento objeto es omitido, a la vez que se agrega un morfema reflexivo en el verbo (-wü). De esta forma, esta construcción es compatible solamente con cláusulas directas, sin morfema de persona objeto paciente (-fi), ya que estas últimas (6d) implican la presencia de un objeto en interacción con la persona sujeto, mientras que aquel morfema señala que una sola persona (sujeto) cumple 
simultáneamente los papeles temáticos de agente y paciente ${ }^{11}$ Por la misma causa, la construcción reflexiva no es compatible con las cláusulas inversas (6g).

(6) a Directa: Sujeto-Objeto/Paciente.

Feymew iñche feypi-n: "Fachi antü [...]" (Coña, 2000:324).

Entonces yo decir-Ind1s este día

"Entonces yo dije: Este día [...]".

b Directa: Sujeto-Objeto/Dativo ${ }^{12}$

Feymew iñche feypi-fi-ñ Kuan [feychi dungu].

Entonces yo decir-Obj3Pac-Ind1s Juan ese asunto

"Entonces yo le dije (a) Juan [ese asunto]".

c Directa (Pseudo-refleja): Sujeto-Objeto

*Feymew iñche feypi-fi-ñ iñche. ${ }^{13}$

Entonces yo decir-Obj3Pac-Ind1s yo

"Entonces yo le dije a mí".

d Directa-Refleja: Sujeto-Sujeto-Objeto/Paciente

*Feymew iñche feypi-wü-fi-ñ iñche.

Entonces yo decir-Obj3Pac-RFX-Ind1s yo

"Entonces yo me lo dije a mí mismo".

e Directa-Refleja: Sujeto

Feymew iñche feypi-wü-n: “[...]” (Coña, 2000:449).

Entonces yo decir-RFX-Ind1s

Entonces yo me dije: “[...]".

f Inversa: Sujeto-Objeto

Iñche, feypi-e-n-ew ñi kiñe choküm (Coña, 2000:462).

yo decir-ObjAg-Ind1s-Obj3 mi un sobrino

"Yo, fui dicho por mi sobrino" (o "mi sobrino me dijo").

g. Inversa-Refleja: Sujeto

*Iñche feypi-wü-e-n-ew ñi kiñe choküm.

yo decir-ObjAg-Ind1s-Obj3 mi un sobrino

"Yo me fui dicho por mi sobrino".

En (7) el sujeto de las cláusulas subordinadas es correferente con aquélla de las cláusulas principales.

(7) a Continuidad de $\mathrm{SN}$ en subordinadas

Wiño-me-y chi malen [Ø] nütramka-lu longko engu (Becerra, 2009:125). volver-DEI-Ind3 la mujer [SUJ] conversar-INF jefe ellos. dos

\footnotetext{
${ }^{11}$ La concurrencia de los morfemas — wü-fi sí es posible en verbos no finitos (v. gr., tami eluwüfiel), ya que en estos casos el morfema- wï indica que las personas prominentes de la cláusula no finita es tanto la primera singular, como la segunda singular. Se sigue, así, el patrón de las cláusulas finitas.

12 En la terminología de Givón (2001:107), "dativo" corresponde a un rol semántico que es un "participante conciente en el evento, típicamente animado, pero que no es el iniciador".

${ }^{13} \mathrm{El}$ asterisco indica agramaticalidad. Este enunciado es gramatical en mapudungún, pero con una función distinta: "Yo le dije "yo"".
} 
"(Fue y) volvió la mujer que conversó con el lonko (=habiendo conversado con el lonko)".

b Feychi wentru ayüi-w-küle-y [Ø] pe-fi-el tañi üñam (Becerra, 2009:125).

Ese hombre alegrar-RFX-EST-Ind3 [SUJ] ver-Obj3Pac-INF su novia

"Ese hombre está contento (por) haber visto a su novia".

En resumen, la principal persona gramatical en mapuche ostenta un amplio rango de las propiedades formales prototípicas del sujeto gramatical: concordancia verbal, orden de palabras, gobierno y control de construcciones. Todas tienen una base pragmática, lo que se sustenta en la topicalidad del sujeto. En cuanto a la segunda persona argumental (la "persona satélite" de Salas, 1979) este trabajo ha asumido - sin explicarlo aún - la pertinencia de la denominación "objeto". Aunque no será motivo de argumentación detallada en este trabajo, adelantamos que esta opción se basa en que el objeto gramatical en mapudungun, corresponde a la segunda relación gramatical más prominente en la lengua, la que presenta propiedades formales - posición relativamente fija- (Arnold, 1996; Rivano, 1988), concordancia parcial $^{14}$ con morfemas verbales, y control sobre algunas construcciones (como fue mostrado, por ejemplo, para el caso de la inversión, vid. supra). Esto se relacionaría a sus propiedades pragmáticas, que la hacen la segunda persona más topical, después del sujeto (vid. infra).

Finalmente, el último argumento de Salas (1979) para desestimar el concepto "sujeto", corresponde a la dificultad de identificarlo en las cláusulas con "incorporación de satélite", ya que en éstas, el verbo no concuerda en número con el sintagma sujeto. Sin embargo, a partir de la definición multidimensional adoptada en esta investigación (Givón, 2001; Keenan, 1976), la concordancia es sólo uno de los elementos formales utilizados para codificar esta función sintáctica. Por otra parte, la particularidad de esta construcción, junto a la jerarquía interpersonal, se enmarcan en una propiedad mayor de la lengua mapuche, que dice relación con las personas gramaticales favorecidas discursivamente para constituirse en tópico (Cfr. Grimes, 1985; Rivano, 1988-1991). Por lo tanto, esta aparente violación a la regla, da cuenta de la concurrencia de la primera y la segunda persona como preferenciales para convertirse en sujeto.

¿POR QUÉ “TÓPICO”?

Como fue anteriormente expuesto, en la lengua mapuche la jerarquía interpersonal de interacción concede preeminencia a algunas personas gramaticales, para convertirse en sujeto gramatical (Arnold, 1996), la "persona axial" según Salas (1979). Tales entidades coinciden con los ejes referenciales del texto (tópicos), lo que favorece su mantención como actantes o interactuantes centrales.

Esto puede explorarse a partir de la definición de tópico, entendido como el mecanismo informativo que enuncia el o los referentes principales de un texto, retomando un referente ya existente en la representación en curso, y manteniéndolo en la atención

\footnotetext{
${ }^{14}$ En mapudungún, la concordancia del objeto depende de factores como su animacidad, humanidad y definitud.
} 
(Givón, 2001). El tópico se refiere principalmente a entidades (sintagmas nominales) y, con menor frecuencia, a eventos (verbos) o estados (adjetivos), aunque estos últimos pueden ser nominalizados para contraer esta función. En términos prácticos, a pesar de que el tópico es estudiado frecuentemente a nivel clausular, debe recordarse su ámbito es el discurso, pues cumple la función de dotar de coherencia a un texto multiproposicional. Ahora, si bien las entidades topicales se manifiestan en la cláusula, y se gramaticalizan preferentemente como sujeto y objeto, un referente no es tópico porque haya sido codificado gramaticalmente como tal (sujeto, objeto), sino que se presenta como tal, porque es tópico en una cierta extensión discursiva (Givón, 2001).

Considerando esta noción, Givón (2001) propone estudiar la topicalidad de un referente a partir de su persistencia catafórica; es decir, de su continuidad en el discurso una vez que tal referente fue introducido por primera vez en el texto. En particular, en este trabajo se explora la persistencia de las entidades que cumplen el rol gramatical de sujeto, en comparación con aquéllas que contraen el de objeto. Con tal fin, se estudiaron siete relatos mapuches ("nütram" y "epew"), extraídos de un texto de enseñanza actual (Opazo et al., 2002), y de un texto tradicional de principios del siglo XX (Coña, 2000). ${ }^{15}$ En total, se trabajó con 49 instanciaciones de la relación gramatical sujeto, y 56 del objeto.

Como resultado, se observa que el sujeto corresponde a la entidad gramaticalizada más topical en la lengua mapuche, ya que el referente se mantiene en promedio en 2,4 cláusulas, en comparación al objeto, cuya persistencia catafórica (PC) es de solo 1,7 cláusulas. Esta diferencia en topicalidad de ambas relaciones gramaticales se profundiza si se contabilizan por separado los referentes sujeto que corresponden a entidades animadas en relación a las inanimadas, con un 3,4 y 0,8 de persistencia catafórica, respectivamente (Tabla 1). En consecuencia, los sujetos animados exhiben una topicalidad notoriamente superior a la del objeto, lo que es concordante con la existencia de la mencionada jerarquía interpersonal de selección de los referentes, para convertirse en sujeto.

\begin{tabular}{l|ll}
\hline Referente & $N$ & $P C$ \\
\hline sujeto & 49 & 2,4 \\
sujeto [+animado] & 32 & 3,4 \\
sujeto [-animado] & 17 & 0,8 \\
\hline objeto & 56 & 1,7 \\
\hline
\end{tabular}

Tabla 1: Número de instanciaciones (N) y medida de persistencia catafórica (PC) de referentes, introducidos como sujeto y objeto en relatos mapuches.

La identificación de la "persona axial" de Salas (1979) como la más topical, completa su caracterización como "sujeto" desde el punto de vista de su motivación

\footnotetext{
${ }^{15}$ Los cuentos que constituyen el corpus son los siguientes: "Nentuaymi tunten duamnieymi müten", "Foyeko ñi eltun mew", "Pichi mara ñi ngülamtungen", "Sumpall", "Treng Treng", "Feychi ngürü afngünenngelu", "Feychi ünüm mogeltuchefe". Los cinco primeros fueron extraídos de Opazo et al. (2002), en tanto que los dos últimos, de Coña (2000).
} 
pragmática. En general, la relación entre pragmática y organización sintáctica está bien reconocida, ya que la segunda se establecería diacrónicamente a partir de la gramaticalización de parámetros funcionales, tales como la referencia, la definitud y la topicalidad (Givón, 2001). Si bien, el estudio de las propiedades de referencia y definitud (propiedades de la función sujeto según Keenan, 1976) está pendiente en la lengua mapuche, es de esperar una correlación entre tales propiedades y la topicalidad.

El rol gramatical sujeto correspondería, ante todo, a la entidad que expresa de forma preeminente, ciertos parámetros funcionales que se relacionan con la identificación y con la referencialidad. Se explica, de este modo, el reconocimiento de que algunas entidades sean más proclives a constituirse en sujeto, en tanto son - frecuente u obligatoriamente- topicalizadas. En el caso del mapudungún, esto incluye la preferencia por las entidades que poseen los rasgos [+animado] y [+humano]. Además, como se señaló anteriormente, en mapuche se ha gramaticalizado el parámetro deíctico, según el cual las personas dialógicas (participantes del acto de habla) tienen la preeminencia para constituirse en sujeto. ${ }^{16}$

A partir de lo anterior, es posible señalar que la cuantificación de la persistencia topical (así como su relación con las propiedades de definitud y referencia), refleja las características de la lengua mapuche, en la que existen restricciones para la codificación de ciertos referentes como sujeto. Así, las entidades inanimadas no son favorecidas para asumir esta función, salvo en cláusulas con verbos monovalentes (normalmente en predicados locativos, atributivos, o con verbos de desplazamiento). ${ }^{17} \mathrm{Al}$ contrario, en interacciones, las entidades animadas son las favorecidas para constituirse en sujeto, lo que se correlaciona con una mayor tendencia a persistir en el discurso por un lapso prolongado.

Es consecuencia, el reconocimiento de Salas (1979) de que no todas las personas gramaticales tienen la misma posibilidad de contraer las funciones sintácticas, no atenta contra el reconocimiento del sujeto en la lengua mapuche. Un comportamiento de este tipo ha sido reconocido en lenguas de inversión verbal (v.gr., algonquiano, cheroqui y chukotko-kamchatka) (Arnold, 1996). Así, del mismo modo en que en la mayoría de las lenguas las entidades que contienen algunos rasgos ( $v . g r$. , [+animado] $v / s$ [-animado], [+humano] $v / s$ [-humano], [+agente] $v / s$ [-agente], etc.) son normalmente consideradas más topicales y, por lo tanto, preferentes para convertirse en sujeto (Givón, 2001). En

\footnotetext{
${ }^{16}$ En general, los paradigmas verbales de las interacciones en mapuche se distinguen — en formas finitas y no finitas - a partir del parámetro deíctico.

${ }^{17}$ En mapuche no es posible codificar un paciente inanimado como sujeto, si coexiste con un agente animado (por ejemplo, equivalente a "mis sembrados fueron arrancados por la liebre": *ñi tukukan em ngedukaeyew mara). La opción, en estos casos, es codificar al padecedor indirecto (primera persona singular) como sujeto-paciente: ngedukañmaenew mara ñi tukukan em (más literalmente: "fui arrancado mis sembrados"). Sin embargo, en algunos casos, podrían ser posibles algunas construcciones que no consideren el "padecedor indirecto" cuando éste tiene un estatus mayor (de la jerarquía interpersonal), pero no sería la opción más idiomática.
} 
mapudungun se favorece el parámetro deíctico (entidades dialógicas $v / s$ extradialógicas), por sobre el iniciador de la acción (agente).

\section{CONCLUSIONES}

A partir de un marco teórico tipológico y funcional se ha demostrado que los conceptos de sujeto y tópico son pertinentes en la descripción de la lengua mapuche; el primero, como descriptor sintáctico y, el segundo, como descriptor discursivo. Del mismo modo, se argumenta a favor de la utilización del descriptor "objeto". Por tanto, los conceptos "persona axial" y "persona satélite (Salas, 1979) son explicativos en el ámbito morfológico para designar a los sufijos de persona verbal, pero no en el ámbito sintáctico ni discursivo. Asimismo, se ha discutido la estrecha relación entre los conceptos sujetoobjeto y tópico, tanto en aspectos pragmáticos de carácter universal como en aspectos particulares de la lengua mapuche.

En relación con lo universal, la emergencia diacrónica del sujeto a partir de procesos de gramaticalización, está motivada cognitivamente por la alta recurrencia de la codificación de los referentes principales de un texto, es decir, los que presentan las propiedades pragmáticas de topicalidad (frecuentemente también las de definitud y referencia, no estudiadas en este trabajo). Como resultado, tales referentes cristalizan distintas manifestaciones formales asociadas a su rol gramatical. En cuanto a lo particular, el mapudungún presenta una tendencia a codificar entidades animadas como sujeto, lo que se verifica obligatoriamente en las interacciones. Esto se asocia a la importancia que adquiere el parámetro deíctico sobre el iniciador de la acción para fijar la principal persona gramatical de una cláusula.

En consecuencia, el reconocimiento de Salas (1971-1979) de las particularidades gramaticales del mapudungún, no hace necesaria la adopción de una terminología sintáctica específica para la lengua mapuche ("persona axial" o "focal"). Por el contrario, se demuestra que el descriptor "sujeto" es totalmente coherente con una perspectiva funcional y tipológica de la lengua mapuche, ya que la principal persona gramatical exhibe una amplia gama de las características prototípicas, universales, de esta relación gramatical.

Universidad de Concepción* Facultad de Ciencias Sociales Barrio Universitario s/n. Casilla 160 C, Correo 3. Concepción (Chile) robecerr@udec.cl 


\section{BIBLIOGRAFÍA}

Arnold, Jeenifer. "The inverse system in Mapudungun and other languages", en Revista de Lingüística Teórica y Aplicada $\mathrm{N}^{\circ} 34$ (1996):9-48.

Augusta, Félix de. Gramática Araucana. Valdivia: Imprenta Central J. Lampert, 1903.

Baker, Mark C. "On Zero Agreement and Polysynthesis", in P. Ackema, P. Brandt, M. Schoorlemmer and F. Weerman (Eds.). Arguments and Agreement. Oxford: Oxford University Press, 2006:289-320.

------ "On the loci of agreement: Inversion construction in Mapudungun", in Proceedings of NELS 33, GLSA. University of Massachusetts, Amherst (2003):25-49.

Baker, Mark C.; Fasola, Carlos. "Araucanian: Mapudungun", in .R. Lieber y P. Stekauer (Eds.). The Oxford Handbook of Compounding. Oxford: Oxford University Press, 2007:594-608.

Becerra, Rodrigo. "Expresión de la causalidad en la lengua mapuche: Un estudio funcional". Tesis para optar al grado de Magíster en Lingüística. Universidad de Concepción, 2009.

Coña, Pascual. Coña ñi tukulpazungun: Testimonio de un Cacique Mapuche. Santiago de Chile: Pehuén, 2000.

Fernández-Garay, A. "La variación actancial en Ranquel", en Estudios de Lingüística Española $\mathrm{N}^{\circ} 13$ (2001).

Givón, Talmy.The genesis of syntactic complexity: Diachrony, ontogeny, neuro-cognition, evolution. Amsterdam: John Benjamins, 2009.

------ Syntax. Amsterdam: John Benjamins, 2001.

------ Functionalism and grammar. Amsterdam: John Benjamins, 1995.

--_-- "Topic continuity in discourse: An introduction", in T. Givón (Ed.). Topic continuity in discourse. A quantitative cross language study. Amsterdam: John Benjamins, (1983):1-41.

Golluscio, L. "Ditransitive constructions in Mapudungun", in A. Malchukov, M. Haspelmath y B. Comrie (Eds.). Studies in ditransitive constructions: A Comparative Handbook, 710-756. Berlín: Mouton de Gruyter, 2010.

Greenberg, Joseph. Language universals. La Haya: Mouton, 1966.

Grimes, Joseph. "Topic inflection in mapudungu verbs", in International Journal of American Linguistics (IJAL) 51, 2 (1985):141-163.

Harmelink, Bryan. Manual de aprendizaje del idioma mapuche: Aspectos morfológicos y sintácticos. Temuco: Universidad de La Frontera, 1996.

Keenan, Edward L. "Towards a universal definition of subject", in C. Li (Ed.). Subject and Topic. Nueva York: Academic Press Inc., 1976:303-334.

Lagos, D.; Riquelme, P.; Núñez, M. T. "La persona satélite del mapudungun: Un análisis desde la gramática del papel y la referencia", en Nueva Revista del Pacífico, № 54 (2009).

Lenz, Rodolfo. La oración y sus partes. Estudios de Gramática general y castellana. Santiago de Chile: Nascimento, 1944.

Opazo, Marlene; Huentecura, Jorge; Hernández, Arturo; Quidel, José y Galdames, Viviana. Guía didáctica para la enseñanza de la cultura y lengua mapuche. Santiago de Chile: Ministerio de Educación, 2002.

Rivano, Emilio. "Topology and dynamics of interactions with special reference to Spanish and Mapudungu". Travaux de l'Institut de Linguistique de Lund, 25. Lund, Suecia: Lund University Press, 1991. 
------ "Morphosyntactic functions in mapudungu", en Revista de Lingüística Teórica y Aplicada $\mathrm{N}^{\circ} 26$ (1988):57-90.

Salas, Adalberto. "Semantic ramifications of the category of person in the mapuche verb". Tesis para optar al grado de Ph. D. State University of New York at Buffalo. University Microfilms International, 1979.

"Terminaciones y transiciones en el verbo mapuche: Crítica y bases para una nueva interpretación", en Revista de Lingüística Teórica y Aplicada 16. (1978):167-179.

------ "Notas sobre el verbo en el mapuche de Chile (IV)", en Revista de Lingüística Teórica y Aplicada $\mathrm{N}^{\circ} 9$ (1971):75-101.

Sapir, Edward. El lenguaje. Introducción al estudio del habla. Ciudad de México: F.C.E., 1994.

Smeets, Ineke. A grammar of Mapuche. Berlín - Nueva York: Mouton de Gruyter, 2008.

Zúñiga, Fernando. "Mapudungun. El habla mapuche". Santiago de Chile: Centro de Estudios Públicos, 2006a.

----- Deixis and alignment. Inverse systems in indigenous languages of the Americas. Amsterdam: John Benjamins, 2006b. 